\title{
VISUAL LITERACY FOR THE 21ST CENTURY
}

\author{
Bozena Supsakova \\ Prof. Dr., Comenius University, Faculty of Education, Bratislava, Slovakia, \\ supsakova@gmail.com
}

\begin{abstract}
The dominance of the pictorial world forms the beginning of the effect of new visual civilisation in the 21 st century. Today, we already know that photograph, film and television are just fist stage of visual era. The modern phenomena of digitalisation and mass communication related to the development of information and communication technologies and Internet, dramatically saturate the pictures and pictorial messages to public space and thus also to our everyday life. Posters, billboards and various visual posts attack us every day with their pictorial messages, trying to influence us while going to the work or school as well as while being on the road for a joy or relax. The presence of visual impulses is perceived also in the public space, for example in shopping malls. In such an environment, their role is to affect our purchasing habits. The information lettering in pictorial form -iconograms- orientate us on the streets, at the stations of mass transport, at the airports, in shopping malls, in tourism regions. Today, Internet and social networks are mainly the source of information mediated in the form of pictures in multimedia form.

In the contemporary world, heavily saturated with pictures and media, our view of what literacy means must be extended, or even re-defined. To read pictures is more than to read and write text, this is the "reading of the world of pictures". The Kaiser Family Foundation Study implies young people devote still greater attention to the pictures in the new media (Internet and social networks). While this was six hours and twenty-one minutes a day in average in 2009 , it is seven hours and thirty-eight minutes a day in 2013 . The numerical data say there has been a significant shift for 4 years and young people pay greater attention to pictorial information, they devote more of their time to them, by one hour and seventeen minutes. We may state that the use of new media has been intensified for recent 10 years, thus also time capacity devoted to media by young people has been increased too, save one exception - the interest in reading has decreased, yet it still consider it to be the basic, non-excludable literacy. Saying it in more unambiguously, text reading gets to the background and the first place is attained by reading, or perception of pictures in digital media.
\end{abstract}

In the article we present a theoretical model of visual literacy and develop new personnel competencies of children for the 21 st century, such as visual perception, visual thinking, visual language and learning visual literacy.

Keywords: visual perception, visual thinking, visual language, learning visual literacy

\section{INTRODUCTION}

The world has never been so saturated with pictures in the hitherto human history as now. The visual culture, covering the phenomenon, is not the new aspect of the social world. The visual imaginations established in the human culture extend through a long history of the development of society - from first 
cave murals through medieval paints and sculpture - up to the new forms of imagination in photograph, film, advertising, video, computer games, and the most recently also in Internet social networks.

Visuality and human being are the interconnected vessels. Malcom Barnard (2001) claims that: "What is visual that has become an important experience in human life. It is more under the influence of visual materials and we are even more dependent upon them" (p. 4). Also Nicolas Mirzoeff (1999) is of a similar opinion when stating that "we can speak of the central importance of feelings in everyday life" $(p .7)$. Several authors are of the same opinion that as if a visual turns in a modern and especially in the post-modern society. In the view of this, M. Sturken and L. Cartwrigh (2001) note "our culture is a visual culture to a great extent. The western culture was controlled by visual media instead of spoken and written mediations of information in the course of recent two centuries. We live in the culture that is more and more infiltrated by visual images with various targets and intended effects"(p. 10).

\section{FROM A WORLD TO THE IMAGE}

Pictures form our everyday experience and lead to the development of the new forms of perception, sensitivity, thinking and understanding of the world. We shift from the verbal perception of reality to the visual perception of reality. In this regards, it is important to define and also specify three typological criteria of an image: function, localisation and technique. Of course, the image fulfils in particular the artistic, information, documentary and advertising function. The technical implementation in the context of the perception of an image as an artefact relates to painting, graphics and sculpture. Also to photograph, film and television images, to the modern digital images and multimedia. Their common feature is the manifold reproductions, where the difference between the original and the copy is wiped out in many cases (this especially relates to digital image). Of course, the localisation of an image relates to a place, a public space, such as the gallery, street, arcade, cultural event, television broadcast or Internet.

Today, we may speak of three historical eras, with the characteristic feature of the prevailing culture: the oral, verbal and visual era. The oral era relates to the spoken expression, the human communications takes place by means of spoken word in it. In this era, the communication space is strictly limited, since the transfer and exchange of information take place "vis-à-vis" - face to face. Second era is related to the discovery of script, and especially book printing, which means all information; human experience and observed phenomena may be spread out to even greater group of recipients, to deliver them from generation to generation. Script and press dynamism the propagation of information and assist with the mass character of culture. In third, visual era, the important role in the interpersonal communication is played by picture. It is the propagator of messages, news and experience, yet mostly emotions, artistic and aesthetic value. An image is something that can be handled by senses, that may be decoded, but it also has an impact on subconscious. It may be read as a text, analytically and in parts, but it may influence the recipient also synthetically in the form of an unbroken idea.

The dominance of the pictorial world forms the beginning of the effect of new visual civilisation in the $21 \mathrm{st}$ century. Today, we already know that photograph, film and television are just fist stage of visual era. The modern phenomena of digitalisation and mass communication related to the development of information and communication technologies and Internet, dramatically saturate the pictures and pictorial messages to public space and thus also to our everyday life. Posters, billboards and various visual posts attack us every day with their pictorial messages, trying to influence us while going to the work or school as well as while being on the road for a joy or relax. The presence of visual impulses is perceived also in the public space, for example in shopping malls. In such an environment, their role is to affect our purchasing habits. The information lettering in pictorial form -iconograms- orientate us on the streets, at the stations of mass transport, at the airports, in shopping malls, in tourism regions. Today, Internet and social networks are mainly the source of information mediated in the form of pictures in multimedia form. We can not only watch but also create video messages and films on the biggest worldwide Internet portal YouTube we send MMS via smartphones, and we take photos and record videos using the intelligent mobile phones. Another example of digitisation and mass communication is web page Pinterest allowing the users to create thematic sets of pictures or photos free of charge. Of course, the contemporary visual expression may be disputable as long as its functionality is concerned. Many times, we are the witnesses of the origin of the world of "hyper-reality" or virtual reality where experience, real pictures or products are replaced with the virtual ones. The immersion into the new "world" is not investigated to such an extent that we would be able to assess the impact of "hyper-reality" onto the emotional and rational world of a human.

Due to the rapid technological development and globalisation, the new millennium we live in brings the new demands on skills. In principle, we face the challenge to manage four key literacies: the information, communication, multicultural and visual one. 
The communication literacy is the ability to communicate in active manner and using a reasonable form and to present information. This is the set of competencies through which we learn, understand, comprehend, and apply all nonverbal and verbal characters and symbols of the corresponding culture serving for communication.

The information literacy relates to the ability to functionally see and efficiently work with information, to be able to search, select and further communicate them. It is based on the use of information and communication technologies and their availability. As long as a man cannot use the information technologies, he cannot achieve information literacy. The information literacy requires substantially more than just the ability to be able to use internet browsers of Google type for information digging. This is the ability to recognize when and what information are needed, the ability to efficiently and purposefully look for the necessary information, to localise the information and information sources, to master the methods, techniques and strategies for information searching. Also to critically evaluate, assess the information, to compare them and on the basis of this select and obtain them) (excerpt, dig, select) from information sources.

The multicultural literacy is the ability to orientate in a different cultural environment. To dispose of the literacy of this type means to be tolerant, to respect manifold cultures, to have a pro-social behaviour without prejudices and barrier towards people coming from various cultures and to accept the differences in the broadest sense, thus also to explicitly position against intolerance, racism and xenophobia.

The term of visual literacy appears in scientific and technical literature more seriously approximately from the half of the 20th century. Within the course of the period, the visual literacy is defined in both narrow and broad sense; however its definition often changes. R. Pettersson (1993) says that "visual literacy is the learnt capacity to exactly interpret the visual messages and to create such messages. The interpretation and capacity to create could be characterised similarly as reading and writing of hard copy texts"(p. 62).

\subsection{Visual Literacy as Multilayer Phenomenon}

To have the visual capacity ${ }^{1}$ that is determined neuro-physically, by age, learning, profession also means to be visually literate. K. Raney (1999) describes the visual literacy as the multilayer phenomena, as the perception sensitivity, at the level of everyday perception of environment (life) and the relations of every individual. Thus we may speak of the cultural space of a new type, in which the life style is created, not only in the field of the creation in the category of perception, the classification schemes or aesthetic judgements. Also the ability to be tolerant and recognize the cultural demonstrations of other social groups and subcultures, for example the culture of children, old people or ethnic groups is important. Furthermore, it includes also the ability of critical thinking and thus related cognition of the means of expression in visual mediation, the recognition of intention with what the picture is created, in the context of history and present time. Last but not least, it is necessary to speak also of the ability to recognize how the picture acts in a certain context, who and why placed it to that context, what group of recipients it should address and why. Also the aesthetic openness is important, in the sense of openness to the emotional and empathic relations and processes, in the ability of visual expression, in the ability to creatively generate any visually perceived picture and object in the broadest sense of word - from oil painting up to web page, from top design up to the common flat furnishing. "The visual literacy relates to a great portion of attained abilities, thus the ability to understand (read) and use (write) pictures, as well as think and learn"(Avgerinou, 2011, p. 26).

It is unambiguously implied by the study of foreign special literature (J. Clark-Baca, J. A. Hortin etc.) that there was hitherto no agreement about the unified definition of the term of visual literacy that would be accepted by the majority of renowned theoreticians - researchers. In general, there is just the agreement about the main aspects expressing it: visual perception, visual thinking, visual language, visual communication and the attainment of new visual abilities by learning. The main reason of the instability of the definition of visual literacy is of course that the groups of theoreticians - philosophers, aesthetes, art scientists, linguists, psychologists, physiologists and neurophysiologists, sociologists - view this term from various points of view and disciplines. The term of visual literacy appears also with the increasing impact of other fields, such as cultural anthropology and cultural theory and semiotics, dealing with the non-language systems of communication. The opinions of the individual groups form a kind of mosaics about the theory of visual literacy. However, the result is the non-homogeneous vies preventing the formulation of a unified

\footnotetext{
${ }^{1}$ The newer definitions are inclined to the term of ability (not skill or competence). The ability is explained as the ability (a) to read/decode/interpret the visual messages; (b) to write/encode/create the visual messages. Third ability is the ability to visually think. Despite that it could seem all this is comprised in the majority of definitions, the ability to visually think was included and explicitly expressed only in newer definitions.
} 
holistic definition. In other words, these theoretical vies provide us with sufficient quota of knowledge about the concept, despite that they are not sufficiently arranged in a single structure and they explain the related phenomena in an insufficient way. Thus they do not provide answer to all questions. However, what is positive is mainly that several theoreticians are inclined to the opinion that art, philosophy, linguistics, psychology belongs also amongst the basic disciplines of visual literacy. We agree with R. A. Braden, J. A. Hortin, J. Clark-Baca and the other ones in their opinion it is necessary to accept visual thinking, visual perception, visual communication and the attainment of visual abilities by learning as the fundamental concepts of visual literacy (Fig. 1). At the same time, it is necessary to state that there was not elaborated in details any relevant theory of visual literacy till now. The reason may be also that the majority of researchers is focused rather on the practical applications and learning of visual literacy. According to them, the theory of visual literacy should stimulate generally valid strategies, therefore they suggest approaching to it from three different angles of view.

1. From theoretical point of view, covering the philosophical, psychological and physiological aspects of learning.

2. From the point of view of the development and cultivation of visual language, including the approaches focused on the recipient, with the aim to help the individuals to become visually literate by means of visual stimuli.

3. From the point of view of education, to establish the starting points embracing the approaches focused on the presentation and improvement of the communication process through visual stimuli (Griffin, Whiteside, 1984, pp. 70-82).

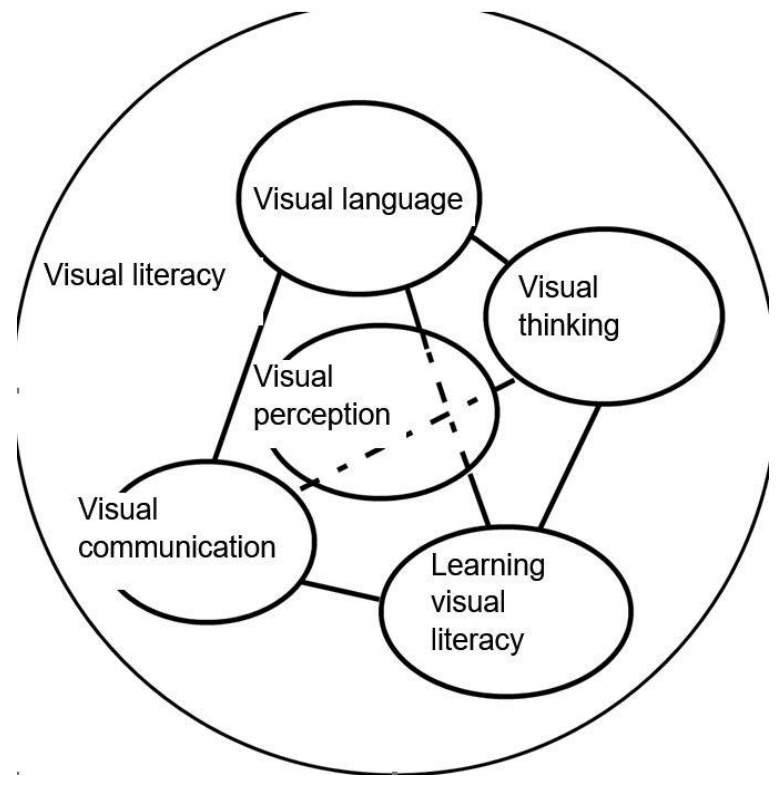

Fig. 1: The theoretical model of visual literacy

\subsection{Visual Literacy - the Interdisciplinary, Multidisciplinary and Multidimensional Space of Cognition}

The Visual literacy covers the impacts and factors of many theoretical disciplines and areas of science and research. Many researchers from various fields explain their opinions and interpretations, writes extensively about visual literacy from their point of view. However, we may see in their expressions and arguments that they stress out different competencies of the literacy, that ones are considered by them to be priority in their scientific field; it is different in exact sciences. Mathematics, physics or chemistry does not include doubleedged symbols and formulas; this implies their communication language is univocal. Of course, the verbal language of an expert must be also clear in the technical description. But when taking prose as an example, being the verbal formation that is open to many interpretations, thus semantically equivocal, then also images are often equivocal. Their authors try to get visual language closer to reality. Visualisations are iconic and the often resemble the object represented by them.

Images speak to us the identical way as our experience does, thus in emotional and holistic way. The 
contents of an image is often more important than the form itself, the product itself, the majority of people is persuaded the images realistically reflect reality. Yet just a few of them realise that "what they think of, what they can see on the pictures, depends upon what they expect they would see and also that they would learn something from that"(Singer, 2010, pp. 39-52). To understand the pictures, their meanings, to feel them in all forms and expressions, means to dispose of the ability to understand both language and the form of communication. Let us illustrate this on an example: When viewing a picture, we cannot read the letters and numbers, yet we are able to identify the shape, form, size, line, composition, rhythm, movement and action. We are able to encode and decode the visual messages and thus we are able to read and write, to express ourselves using visual language. The visual pictures have the power to connect our senses. What we need today is the alphabetisation and literacy of the new age. With regards to the predominance of pictures over text information we may call the ability the visual literacy.

Identically as the traditional literacies, also visual literacy is culturally specific despite that there are universal symbols or visual patterns having a global character. The images as well as pictures and other visuals are cultural products shared by the individuals and according to Singer, "the individuals sense them individually too"(Ibid). Linguistic and cultural differences may have an impact on the efficiency of visual perception. This is the reason for creation of verbal and visual messages in such a way they would suit every group of perceivers. If there is no discourse and pictures are not sufficiently analysed, interpreted, they evidently would not correctly explained and understood.

In the contemporary world, heavily saturated with pictures and media, our view of what literacy means must be extended, or even re-defined. To read pictures is more than to read and write text, this is the "reading of the world of pictures." The Kaiser Family Foundation Study (2010) implies young people devote still greater attention to the pictures in the new media (Internet and social networks). While this was six hours and twenty-one minutes a day in average in 2009 , it is seven hours and thirty-eight minutes a day in 2013 . The numerical data say there has been a significant shift for 4 years and young people pay greater attention to pictorial information, they devote more of their time to them, by one hour and seventeen minutes. We may state that the use of new media has been intensified for recent 10 years, thus also time capacity devoted to media by young people has been increased too, save one exception - the interest in reading has decreased, yet it still consider it to be the basic, non-excludable literacy. Saying it in more unambiguously, text reading gets to the background and the first place is attained by reading, or perception of pictures in electronic media. According to one of the surveys in the USA children (Kennedy, 2013) from the families of a middle class at the age up to 5 years read thousand hours a year (2.74 hours a day), however children from lowincome groups of inhabitants read just a hundred hours a year ( 0.27 hours a day), thus ten times less. This implies that the social status and family environment significantly participate in the development of literacy in general and thus also in the perception of visual literacy. Every negative tendency in reader's ability has its consequences, even more when we know that just the reading with understanding supports creativity, develops imagination, the ability to create pictures.

\subsection{Visual Literacy - the Form of Critical Thinking}

All we can see around is an image. Thanks to our vision we can perceive up to 90 per cent of information about the world. The surveys prove that the non-text (pictorial) information is read by us even 90-thousand times faster than the text one. When viewing a certain object, we can see it at first and on the basis of this we can describe it. When we are able to describe it, then we can analyse it and subsequently interpret it. In the final stage, we can create meanings on the basis of this perception (Fig. 2). In other words, we cannot remember everything we can see, however visual literacy gives us the ability to create (construe) the meanings from pictures. This is not literally the intellectual ability but the important form of critical thinking supporting our intellectual capacity and integrating the potential of our senses. Especially now, in the digital age, it is inevitable to integrate dual form of information: picture and text, despite that finally everything is a picture since also text, when perceived by vision, is the part of visual literacy.

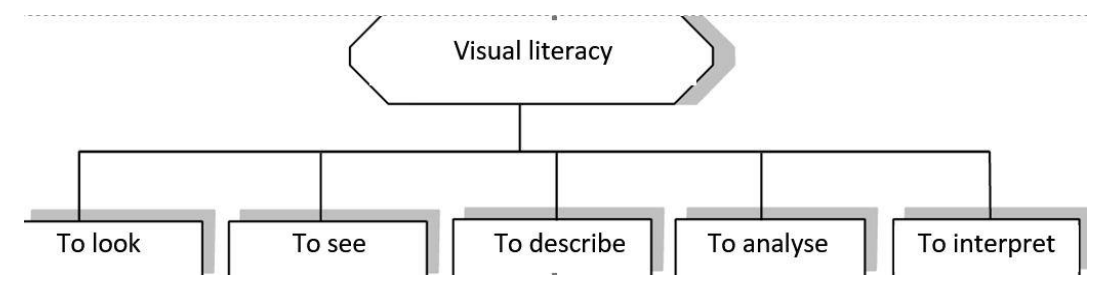

Fig. 2: Visual literacy: To look - To see - To describe - To analyse - To interpret

Visual literacy is not a skill in the common sense of the word that would be used by a human as a tool. It is 
the form of critical thinking increasing our intellectual capacity and allowing to:

- Interpret the contents of the images.

- Investigate the social impact of the images.

- Dispose of the ability of internal visualisation.

- Discuss about their meanings with target group (to characterise who they are intended to),

- Visually communicate.

- Read and interpret the images.

- Create opinions about the accuracy, validity and richness of the images.

\section{CONCLUSION}

Visual literacy is the ability to develop meanings from everything we can see, to find the sense in everything we can perceive. Visually literate man can read and write using the visual language since he/she masters the process of emission and reception of messages by means of images. A man with average education can read the information in pictorial expression and picture form, he/she is able to orientate in the multimedia world. However, the problem is the contemporary concept of education supports rather the development of reading literacy (the understanding of the meaning of letters and numbers) and computer literacy, but neglects sensual literacy, dealing mainly with the convertibility of received and handed out information through all sensual channels. In order to be visually literate, we need to constantly develop and improve our abilities, to train our visual capacity, thus to learn how to interpret the meanings of pictures and also how to create the meanings from the presented information in the form of pictures. Visual literacy helps to develop also the verbal (written and spoken) speech. We share the opinion of Avgerinou (2003) that the abilities of visual literacy can be: (a) learn, (b) teach, (c) developed and improved. Visual literacy, we are interested in, is the alphabetisation and literacy of the new age. This should be our priority in the entire society, including the anchorage of the given problem in the state curriculum documents, with the aim to develop and cultivate the visual literacy in childhood already.

\section{REFERENCE LIST}

Avgerinou, M. D. (2011). Toward a Cohesive Theory of Visual Literacy. In: Journal of Visual Literacy, Vol. 30, No. 2, pp. 1-19.

Avgerinou, M. D. (2003). A Mad-Tea Party No-More: Revisiting The Visual Literacy Definition Problem. In: R. E. Griffin, V. S. Williams, L. Jung (Eds.). Turning trees. Loretto, PA: IVLA, pp. 29-41.

Braden, R. A. (1996). Visual Literacy. In: Journal of Visual Literacy, Vol. 16, No 2, pp. 9-83.

Clark-Baca, J. (1990). Identification By Consensus Of The Critical Constructs Of Visual Literacy: A Delphi Study. Doctoral Dissertation. East Texas State University.

Hoffman, D. (1998, 2006). Visual Intelligence. How We Create What We See. New York - London, W.W. Norton \& Company.

Hortin, J. A. (1994). Theoretical Foundations of Visual Learning. In: Moore, D. M.\&Dwyer, F. M. (Eds.). Visual literacy: A spectrum of visual learning. Englewood Cliffs, NJ: Educational Technology Publications, pp. 5-29.

Griffin, R. E., Whiteside, J. A. (1984). Visual literacy: A model for understanding the discipline. In: A. D. Walker, R. A. Braden, L. H. Dunker (Eds.). Visual literacy: Enhancing human potential, pp. 70-82. Blacksburg, VA: Virginia Tech University (ERIC Document Reproduction Service No ED131837).

Kaiser Family Foundation. Generation $\mathrm{M}^{2}$. Media in the Lives of 8- to 18- Year- Olds, 2010, p.1. [online]. [cit. 2015-03-07]. On line: https://kaiserfamilyfoundation.files.wordpress.com/2013/04/8010.pdf

Kennedy, B. (2013). Visual Literacy. On line: https://www.youtube.com/watch?v=O39niAzuapc

Mirzoeff, N. (1999). An Introduction To Visual Culture. London: Routledge.

Pettersson, R. (1993). Visual Information. Englewood Cliffs, NJ: Educational Technology Publications. 
Raney, K. (1999). Visual Literacy and the Art Curriculum. In: Journal of Art and Design Education, Vol. 18, No 1.

Singer, W. (2010). The Brain's View Of The World Depends On What It Has To Know. In: A. Berthoz, Y. Christen (Eds.). Neurobiology of „Umwelt“: How living beings perceive the world. Berlin: Springer, pp. 39-52.

Smith. M. (2008). Visual Culture Studies. Los Angeles, London, New Delhi, Singapore: Sage Publications Ltd.

Stafford, B. M. (1999). Visual Analogy, Consciousness as the Art of Connecting. Cambridge, London: The MIT Press.

Sturken, M., Cartwright, L. (2001). Practices of Looking. An Introduction to Visual culture. Oxford: Oxford Universitz Press.

Šupšáková, B. (2013). Reflection of the Primary Schoocurriculum from the Media Literacy Perspective in Slovakia. In: ICT in Education Design Processes, Materials, Resources. Zielona Góra: Oficyna wydawnicza Uniwersytetu Zielonogórskiego, Vol. 3, pp. 159-172.

Šupšáková, B. (2013). New Media and Social Networks as a New Phenomenon of Global Access to Information and Education. In: US-China Education Review A, Vol. 3, No. 8, pp. 623-635.

Šupšáková, B. et al. (2014). The Media Literacy of Children and Young People. Bratislava: Iris.

Šupšáková, B. (2014). Preferences of visual language and symbols in the digital age of youth. In: Ireland International Conference on Education (IICE-2014), pp. 76-82. 